\title{
TEMPOS E VIDAS EM MEIO À CIDADE
}

\section{Paula Ramos Smith, Ana Paula Figueiredo Louzada}

\section{Resumo}

Trata-se de uma pesquisa que intenciona tomar contrações e dilatações do tempo, em suas relações com os modos de vida no contemporâneo, na cidade. Há uma tentativa de delinear experimentações, que por meio de desvios e desalinhos, desenham um tempo rizomático. Para tal, a pesquisa primou pela processualidade em seus fazeres, forjando seus aliados pela conversa, acompanhando olhares da cidade de Vitória (Espírito Santo) em quatorze de seus habitantes, que dialogam com os modos de habitar a cidade e sua relação com uma produção de subjetividade. Para tanto, nas trilhas especialmente de Pélbart, Deleuze e Foucault, encontrou-se seus intercessores.

\section{Palavras-chave:}

Tempo. Vida. Cidade.

\section{Abstract}

This is a research that intends to take contractions and dilatations of time in its relations with ways of life on the comtemporary, in the city. There's an attempt of of sketching out experimentations using diversions and disorders, draws a rhizomatic time. In order to achieve this, the research topped by processuality on its makings, forging its allys by conversation, accompanying views from the city of Vitória (Espírito Santo) by fourteen of its citizens, by each is possible to dialogue with ways of dwelling the city and its relationship with a production of subjectivity. To achieve this, on tracks, specially, found on Pelbart, Deleuze and Foucault its intermediators.

\section{Keywords:}

Time. Life. City. 


\section{Introdução}

Pensar o contemporâneo como um regime de temporalidade com implicações na produção de subjetividade, em uma determinada cidade; mais precisamente: trata-se, aqui, de parte de uma pesquisa que teve como propósito acompanhar algumas variações do tempo, entre 2010 e 2012, pela cidade de Vitória, ES, através de algumas vidas que a habitam.

Aquilo que se convencionou chamar tempo contemporâneo, e que está incrustado nos modos de vida que perpassam a cidade é o disparador dos tencionamentos que aqui se encontram. Em diálogo, um certo "tempo contemporâneo" e um tempo outro, ou o outro do tempo - esse tempo a se fazer.

Tomar, então, o tempo contemporâneo/atual como um tempo "já dado", um tempo de definições e relógios e tentar extrair dele seu extemporâneo/virtual. Logo, o que se chamaria de um tempo outro, seria um tempo de variações, de criações, e, estaria no seio desse mesmo "tempo contemporâneo".

Para tanto, nos utilizamos do dispositivo da escuta e registro de vidas que habitam essa cidade e expressam, através de sua matéria-prima, que um tempo já dado não cabe em uma vida por se fazer. Vidas que experimentam um tempo outro, que precisamente forja desvios e desalinhos, em meio aos quais pode delinear-se conceitualmente um tempo rizomático. Rizoma, para nós, é uma abertura, são os virtuais e suas atualizações. Um sistema não de pontos, mas de linhas. "Uma multiplicidade não tem sujeito nem objeto, mas somente determinações, grandezas, dimensões que não podem crescer sem que mudem de natureza" (DELEUZE, 2009, p. 16).

Com essas intenções de pesquisa, e uma aposta metodológica arriscada, nos dispusemos a acompanhar modos de viver a cidade, experimentações temporais e vidas.

\section{Ecos e sussurros: caminhando pelas ruas da cidade de Vitória}

Existe, ao menos, um som que se expande pelas ruas, som que vem de sístoles e diástoles de vozes de vidas que re-existem, pela cidade. Re-existem, porque existem resistindo ou fazem de sua existência um resistência. Sístoles 
porque, minimamente, ora se expandem em criação ativa; e diástoles porque, minimamente, ora se comprimem em dureza e condicionamento de um modo de vida colocado no contemporâneo.

Contudo, não se tratam de oposições, são sístoles e diástoles de uma vida; de cada vida, que ora se apresentam em ação, ora em contração. Sístoles e diástoles como uma ética de vida, um exercício de si, na cidade. Esta pesquisa está marcada por essas dilatações e contrações através das vozes que exprimem suas experiências. Sem ordem estabelecida, nos deparamos com falas desencaixadas a respeito de uma urbe. E é nessa urbe, que ao encontrar com habitantes que a vivem, nos deparamos com muitos dilemas acerca das relações com o tempo.

Este tempo contemporâneo que é demasiadamente sentido no cotidiano da cidade, parece manipular afazeres e governar vidas. Poderíamos arriscar que está imbricado em um modo de gestão disciplinar. O que é chamado de tempo parece se tratar de um cronômetro que não para - um mero contador defeituoso de todas as horas, porque além de não parar de contar, ele acelera a vida e a existência.

O tempo cronológico além e aquém que extrapola o próprio cronológico, que, ao mesmo tempo, o infla e o subtrai. Esta

[...] velocidade reduz o tempo e o espaço ao mínimo, ao nada. Contração da Terra e do Futuro, contração telúrica e histórica, tirania do movimento, mas fim da moção. Neste regime de temporalidade, com o qual o homem pensou que ia ganhar o Tudo, ficou com Nada: é difícil ter um espaço, uma história, um tempo vivido, um território, expandir-se etc. (PELBART, 1993, p. 42).

Deleuze (2008) afirma que no auge da Revolução Industrial, dentre outras coisas, começou a domesticação e repartição ferrenhas do tempo e do espaço, o confinamento do tempo em favor do espaço, com a espacialização do tempo através das horas, minutos, segundos. Necessitava-se de disciplinar o tempo, os corpos, a vida.

Nas sociedades de disciplina não se parava de recomeçar (da escola à caserna, da caserna à fábrica), enquanto nas sociedades de controle nunca se termina nada, a empresa, a formação, o 
serviço sendo os estados metaestáveis e coexistentes de uma mesma modulação, como que de um deformador universal (DELEUZE, 2008, p. 221-222).

E hoje? O que mais nos afeta em relação ao tempo, por vezes não parece ser a sua falta? Não nos parece que esse tempo extrapola os relógios e as horas já não cabem? Não nos remete à sensação de insuficiência, de estar sempre em falta?

No bojo das grandes cidades não escapamos desta aceleração, ao contrário. Vivenciamos, por conta deste funcionamento, um ritmo exaustivo. A produção mercadológica, exigida com tanto rigor e categoria pelo capitalismo contemporâneo, que a cada dia se torna mais voraz e empresarial, modula a vida numa homogenia maçante, através de mecanismos mais variados de controle.

O estudo sócio técnico dos mecanismos de controle, apreendidos em sua aurora, deveria ser categorial e descrever o que já está em vias de ser implantado no lugar dos meios de confinamento disciplinares, cuja crise todo mundo anuncia. Pode ser que meios antigos, tomados de empréstimo às antigas sociedades de soberania, retornem à cena, mas devidamente adaptados. O que conta é que estamos no início de alguma coisa (DELEUZE, 2008, p. 225).

Somos convencidos e nos convencemos de como se deve viver, o que se deve fazer, que carreira seguir, que carro comprar, onde e como morar, que último modelo de celular atenderá melhor nossas necessidades; como também, somos cooptados por um "tempo" imposto, "compartimentalizado", sucessivo e obediente. E, que, hoje, assume um tônus ainda mais estressante e veloz, parecendo nunca ser suficiente. A aceleração da vida chegou a tal ponto, em que a frase mais corriqueira a se ouvir no contemporâneo, é: "não tenho tempo". Este tempo, criado e produzido por uma lógica capitalista, está, pode-se dizer, a serviço desta mesma doutrina dos corpos, da vida. Para Guberman (2009), a mecanização do homem, produzida pela revolução industrial, foi substituída pela automação deste homem na era cibernética. Mais uma vez, voltando às trilhas de Pelbart (1993), o lema do capitalismo foi outrora o do "tempo é dinheiro":

[...] era preciso fazer o máximo no mínimo de tempo, maximizar a produtividade, deslocar-se na maior velocidade possível, em 
suma, economizar tempo em todos os sentidos. Mas nas últimas décadas assistimos a uma mutação a esse respeito que mal chegamos a entender. Não se trata mais de ganhar tempo, porém de abolir o tempo. O ideal tecnocientífico contemporâneo consiste em absolutizar a velocidade a ponto de dispensar o próprio movimento no espaço, anulando assim não só a geografia e o tempo de duração desse deslocamento, mas a própria ideia de espaço, de tempo e de duração. É o ideal do tempo zero e da distância zero (PELBART, 1993, p. 32-33).

No entanto, aquele modo de vida em que o trabalho se resume muitas vezes ao soar "madrugal" do despertador e, mais tarde a chegada diária à poltrona que espera em frente ao computador, que se acomoda obediente, na mesa cinza ou bege do escritório - o ponto que se bate de 7 às $17 \mathrm{~h}$, diariamente, este, já não corresponde mais à realidade dos dias de hoje, não só. E está a cada dia mais extinto, mais metamorfoseado. Não vivemos mais o lema do tempo dinheiro, porque nessa época ainda se tinha a dimensão do tempo como algo ao qual nos pertencia, ainda achávamos que ele nos compunha, ainda que de um jeito esquisito. Hoje, apartado, vivemos algo que parece estar no meio. Confluência de confinamento e controle nos aponta à cronopolítica que

[...] está em curso e os desdobramentos ainda são desconhecidos, mas que implica necessariamente no declínio das nossas atividades as mais cotidianas. Um achatamento temporal que proporciona um presente eterno, sem história para trás nem para frente, sem passado nem futuro. Presente sem espessura, ilusão da imortalidade que desconhece o começo e o fim, a morte e o imprevisto, que só integra o desconhecido enquanto probabilidade calculável. O paradoxo é que a desmaterialização provocada pela velocidade absoluta equivale a uma inércia absoluta. Estranha equação em que coincidem velocidade máxima e imobilidade total (PELBART, 1993, p. 34).

Não vamos, tão somente, nos encerrar em lugares fechados e depositar neles boa parte das horas de nosso dia. E ainda que o façamos, estamos sempre conectados com outros lugares através das redes, dos celulares, da internet. Com isso, habitamos uma infinidade de lugares que já não são físicos.

E nesse caminhar marchante, ainda que sejamos endereçados a vários "espaços", estamos costumeiramente habitando certo lugar, certa cidade. Neste 
trabalho, nos voltamos para a cidade de Vitória. As cidades seguem determinados padrões/ modelos, afirmamos, com isso, que a cidade de Vitória, com aspirações a metrópole, aos solavancos, caminha cada vez mais célere para este destino, neste sentido. Vitória também quer fazer parte dessa mundialização das cidades globais, e suas semelhanças tão intrínsecas. Podemos mudar de país, as cidades se assemelham naquilo que Ihes seria, talvez mais distinto, sua forma de viver, seu modo de vida, sua temporalidade.

Essa degradação está ligada ao desemprego, à política de relocação de certas empresas e à instabilidade econômica, social e geográfica que resulta do abalo global da forma de vida. Pois os sobressaltos da cidade e da sociedade urbana hoje são as testemunhas de uma revolução que tenta se generalizar (e, nesse sentido, 'finalizar a história'), mas da qual percebemos, a cada dia, os efeitos desestabilizantes. A instabilidade é a versão obscura da mobilidade que associamos aos aspectos mais dinâmicos da economia (AUGÉ, 2010, p. 35-36).

Sendo assim, vivemos nesta cidade, como em tantas outras, a lógica do metatrabalho, não é mais em um lugar fechado que se trabalha, não só. Hoje o trabalho se dá em casa, no aeroporto através de laptops, tablets e engenhosas máquinas, cada vez menores, que se incorporam aos celulares e às nossas vidas, e viram potentes computadores que estão a acompanhar esta demanda que não cessa e sempre a pedir mais, mais, mais. O que nos é pedido hoje é exatamente o nosso tempo - com ele, o viver, o como viver, onde viver. Numa tal época, que, em boa medida, já distorcemos a própria dimensão do tempo, e estamos a perder a do lugar, a da cidade, há, ainda, tempo para a paralisia? Para o ócio, para a desconexão? Mais do que isso: por que ceder a este modo de vida? Por que não parar? Há ainda tempo ou ele nos falta, mesmo?

Afirmamos que se alguma coisa nos falta é a própria possibilidade de viver inventivamente: de ter as rédeas de nossa própria vida governadas por nossas mãos, se trata de não ceder ao movimento frenético e insensato de um sem fim de atividades e contingências que nos levam a movimentos autômatos, mecanizados, repetitivos e falsamente vistos como falta de alguma coisa, no caso, do tempo. Seria, justamente, perceber que a falta de tempo é apenas uma das vendas que estão em nossos olhos, e seguimos exercendo o máximo que nos 
é exigido - corpos docilizados, obedientes. Somos impelidos por um sentimento de incapacidade, de falta, que nos leva a sempre querer fazer mais, a precisar realizar, a precisar "correr atrás do tempo perdido".

Vivemos, então, uma espécie de demanda que não cessa; invariavelmente conectados - não podemos nos desconectar? "É fácil fazer corresponder a cada sociedade certos tipos de máquina, não porque as máquinas sejam determinantes, mas porque exprimem as formas sociais capazes de thes darem nascimento e utilizá-las" (DELEUZE, 2008, p. 223). Nesta emaranhada trama, temos na cidade de Vitória, um lugar antagônico e complementar, que demonstra seu processo social, político e econômico muitas vezes conflituoso e complexo.

Esta cidade não escapa a um funcionamento acelerado como as tantas outras do país e do mundo. Apontada pelas recentes pesquisas e pela mídia como uma, entre as dez principais cidades para se fazer carreira, e a segunda, no Brasil, para se morar, não deixa, contudo, de apresentar um crescimento desmedido, devido, entre outras coisas, à expansão dos setores de petróleo, mineração e portuário.

Todavia, vale ressaltar, Vitória é uma das menores capitais do país: uma ilhota. E na condição de Ilha, uma pequena Ilha, não consegue abrigar todos seus trabalhadores em casa, tornando-se, muitas vezes, a cidade do trabalho. Muitas pessoas que trabalham em Vitória moram nas cidades vizinhas, em Vila Velha, na Serra, em Cariacica, ou seja, na Grande Vitória.

O que esperamos da vida na cidade? O tempo na cidade... Ora, falta; ora, não importa. E alguns paradoxos emergem: na cidade um tempo que é necessário para a criação dessas outras conexões com a vida, com o existir, e, do mesmo modo, um tempo no qual estamos inscritos, o contemporâneo que se coloca de modo acelerado. Uma questão nos inquieta: o que se cria em meio a isso?

Como forjar na cidade tempos outros que possibilitem vidas singulares? Com esta e outras questões, nos encaminhamos a alguns habitantes desta cidade. Como estes habitantes vivem esta cidade? O que esta lhes faz sentir? Com o quê se conectam? Como resistem, re-existem? Como inventam 
outras cidades? Como se fazem caber? Como já não cabem? Como criam suas próprias formas de existir nesse tempo? Algumas perguntas que balizam as conversas que estão abertas às mais variadas modulações e temporalidades.

Vozes que atestam uma cidade dura, quente, corrida. Vozes que revelam uma cidade litorânea onde a esperança ombreia com a luta, vozes que falam de uma vida ativa, política, que falam de um atuar na cidade, vozes, enfim, que se esbarram dissonantes em suas afirmações e práticas.

Longe da perspectiva do pesquisador que faz perguntas certeiras atrás de respostas pré-formadas nos rastros das perguntas já embrenhadas em suas respostas, nos pusemos a conversar com essas pessoas, munidas, especialmente, de uma curiosidade-inquietação: como nos movemos em meio à cidade que funciona dentro uma temporalidade estabelecida? Como criar brechas? Mas, como curiosidade-inquietação não é roteiro, nos pusemos a travar diálogos, muitos feitos e desfeitos, quatorze deles registrados e transcritos, que nos levaram a outras tantas perguntas.

Perguntas-denúncias de uma lógica homogeneizadora do tempo na cidade contemporânea, contudo, nossos habitantes citadinos insistem em apontar fissuras, brechas. Das estátuas aos tempos inúteis, esses habitantes nos convocam a uma escuta outra do tempo e da vida.

Foi necessário exercitar uma outra escuta do tempo, bem como mudar as lentes "de ver" a cidade, convidando tais habitantes a nos mostrar seus olhares.

Em Aracaju fiz um trabalho com as fateiras, mulheres que trabalham com fatos de boi, vísceras de bois, elas trabalham especificamente com isso. Então a gente começou a perceber que esse trabalho estava em vias de se extinguir, porque as empresas que são credenciadas pelo estado para fornecer carne, não estavam mais entregando os fatos com a mesma qualidade. Ninguém quer mais trabalhar com fato, que é uma coisa que hoje em dia já se criou uma sensibilidade, você tem nojo daquele tipo de mercadoria. A gente pegou o trabalho da fateira como um trabalho de artesão mesmo, porque à medida que ela vai limpando uma língua de boi, vai tirando as camadas, vai tecendo narrativas sobre a vida, fazendo aconselhamentos com as pessoas, então, a gente está tendo ali na feira uma outra temporalidade, sabe? Tipo, as pessoas passavam lá mesmo sem 
comprar nada e ficavam meia hora, 40 minutos conversando com dona Meire e Duquinha. Aí a gente começou pegar essas coisas, como a narrativa engendra uma outra temporalidade, talvez um tempo mais lento, enfim (SANTOS; LOPES; PROTÁZIO, 2010).

Um trabalho que se extingue, um narrar à vida em meio aos fortes cheiros e burburinhos de uma feira, um jeito outro de versar o trabalho e fatiá-lo em meio aos outros. Vísceras e vozes... vozes e vísceras que confundem-se, condensam-se... é o cheiro da víscera que, muitas vezes, embarga o tom da voz, é a textura da língua do boi, que, em alguns momentos, faz calar a língua humana. Composições e experimentações inventadas em meio a visceralidades, numa outra cidade, Aracaju. Vozes entoadas que disparam uma vontade de conhecer Dona Meire e Duquinha, suas mãos e oralidades loquazes, vontade de conhecer seus interlocutores não nomeados.

Quiçá, deixar o corpo misturar-se às sonoridades fatiadas pela língua. É, em meio a essa vontade encarnada que se encontra um morador de Aracaju, recém-chegado em Vitória. Nesse fragmento-fala, indícios de uma temporalidade outra sentidas pelo transeunte da feira.

Um outro habitante e um outro cenário se delineiam:

Esses dias estava falando com um amigo meu, íamos marcar uma reunião em Vitória, no Centro, e eu pedi que fizesse depois das 16h, pra evitar tráfego e calor. O tempo na cidade eu acho que está muito tumultuado e muito cansativo, porque as pessoas estão vivendo dentro de um horário chamado comercial e onde tudo funciona dentro do mesmo tempo. É um tempo concorrido, um tempo de filas, onde você está concorrendo com muita gente um pouco de espaço, mesmo. Todo mundo tem hora para cumprir (ENTREVISTADO).

Todo mundo tem hora para cumprir, lema? Tempo concorrido, tempo comprimido? Como se forja uma relação tempo-cidade? Como se traceja temporalidades, composições de cidades? De que modo vivemos essa relação com o tempo corrido, que, por vezes, apaga os vestígios de outras composições, em um processo de homogeneização acelerado?

A cidade vai ficando mais homogênea, esses marcos vão criando uma tipologia de cidade, né? E aí o que a gente vê é isso, a gente vê um tempo que é feito pra não sentir, um tempo cronos tão 
forte, tão intenso nas suas marcações e nos seus alarmes; parece que toda hora a gente tem vários alarmes e é preciso desligar. Porque tipo assim, é a hora de buscar o menino na escola, é a hora de ir pra aula, é a hora do almoço é a hora de fazer o exercício, é a hora... cadê a hora de viver alguma coisa de verdade, sabe? Cadê o tempo inútil? Cadê a inutilidade do tempo, a inutilidade sensível onde a gente pode viver uma cidade de outra forma? Onde a gente pode se relacionar com o outro de outra forma? Onde a gente pode se relacionar com a cidade de outra forma? (ENTREVISTADO).

Um tempo para não sentir, sobre demarcações de alarmes, cortes, fatias de tempo-uso, de tempo-útil. E um tempo outro? Convoca-nos a pensar em saltitantes perguntas esse habitante citadino.

Eu vim de outra cidade, eu vim de uma cidade que é uma grande metrópole. Então, esta cidade (Vitória) me causa muito prazer porque é uma cidade bonita, é uma cidade que não tem arranha céu, não é uma cidade que a gente pode chamar de selva de pedra, que foi dessa cidade que eu vim. Eu vim de uma cidade que me causava angústia, quando eu abria a janela e só via cinza, só via chuva, só via prédio. São Paulo? Sim. Então, óbvio, quando você chega numa cidade que se consegue ver o horizonte, enxergar o horizonte, que tem o mar, que não tem fim, isso é muito legal. Você ir trabalhar e fazer o trajeto caminho do mar, porque a gente só tem duas formas de chegar no trabalho até o Centro, ou vai pela orla ou vai pelas montanhas - é fantástico. Não se tem vontade de ir embora de uma cidade como essa (ENTREVISTADO).

Cidade-experiência, cidade-memória. Cidade bonita, no dizer do habitante, vindo de outros ares gris. Vitória, cidade-mar, de trajetos sinuosos entre montanhas e mares. Um olhar-outro para sentir uma cidade-outra, menos sufocante, mais aberta em suas possibilidades de existir. Será que Vitória, na boca de seu habitantes, grita por outros olhares?

Fiquei pensando, porque eu sou de Minas, aí eu tive uma vivência assim de cidade-roça, meu pai tinha um sítio e tal [...] e a experiência da cidade urbana me lembra muito a coisa da luz, a cidade é muito mais clara, à noite, né? A cidade dorme mais tarde, o tempo da cidade e da roça é muito diferente, no tempo da roça você dorme quando anoitece e acorda quando amanhece, porque não tem luz, e o tempo da cidade não, se faz. Você pode apagar e acender a luz, dependendo de onde você esteja, então é um outro 
ritmo [...]. Eu lembro muito de sapato, eu gosto muito de andar descalça e eu andava muito descalça na roça, e na cidade a gente anda muito de sapato, até hoje não gosto de sapato fechado, uso muito sandália, dificilmente tênis, sapato fechado me incomoda, esquenta o pé, porque na verdade, na verdade, eu gosto de ficar é sem sapato [...]. A cidade tem muita hora, o campo não tem muita hora, tem sol, tem chuva, tem dia e noite, é um outro jeito de contar o tempo (ENTREVISTADO).

Sapatos para se andar numa cidade iluminada. Com asfalto sob os passos e postes sobre as testas, segue-se, firme em tentar encontrar nesta cidade, uma cidade-outra, uma cidade-escape. Não só a cidade do trabalho, que anteriormente se afirmou, não só a cidade útil, mas uma cidade de sentidos, também, uma cidade composta de sensações, de atravessamentos outros, que irrompem esse modo duro, que igualmente compõe esta cidade.

A cidade assume, então, várias facetas, partes caleidoscópicas, unidas - como no manto remendado de Arlequim. Onde cada olhar se transforma em uma cidade - porque se olha junto e não sobre. Onde cada olhar fala de uma subjetividade, de um tempo. Pulsando a cidade, através destes diversos olhares, inúmeras cidades, ficção da cidade, ficção da vida: invenção e construção.

Passa uma moça balançando uma sombrinha apoiada no ombro, e um pouco das ancas, também. Passa uma mulher vestida de preto que demonstra toda sua idade, com os olhos inquietos debaixo do véu e os lábios tremulantes. Passa um gigante tatuado; um homem jovem com os cabelos brancos; uma anã; duas gêmeas vestidas de coral. Corre alguma coisa entre eles, uma troca de olhares como se fossem linhas que ligam uma figura à outra e desenham flechas, estrelas, triângulos, até esgotar num instante todas as combinações possíveis, $[. .$.$] . Assim, [\ldots]$, consumam-se encontros, seduções, abraços, orgias, sem que se troque uma palavra, sem que se toque um dedo, quase sem levantar os olhos (CALVINO, 2008, p. 51-52).

Assim, entre balanços de transeuntes - seus barulhos, seus odores, seus equipamentos, bolsas, maletas e tantas coisas que carregamos para além do visível - borbulham experimentações, em meio à paisagem urbana.

Abrolham questionamentos que nos fazem pensar se há uma fatalidade unívoca da vida ou se podemos ousar, no seu limite, causando algum 
reboliço no que pensamos estar estratificado. Entre as artes de governar, fissuras de modos de existir se compõem. Sempre há um hiato para a paralisia, para o ócio, para a desconexão - sempre se pode construí-lo. Sempre? Sempre! Basta haver vontade de potência afirmativa.

Entre corpos e cidades, rondam acontecimentos, vai-se construindo contornos flexíveis para uma proposta, uma proposta que vem de um samba, de uma musicalidade que nos remete a uma dança, a um dançar: dando e pedindo ao/do corpo movimento e paralisia, contração e dilatação, Aion e Cronos, sístoles e diástoles do tempo, no tempo. Fazendo a cidade falar, falar seus moradores e as inúmeras cidades que a compõem por suas vozes.

Nesse momento, a cidade que me vem à cabeça é a mais próxima de mim, porque eu já tive muitas sensações em cidades diferentes, né? Acho que cada cidade também tem algumas características que são comuns às cidades e por isso são chamadas cidades, assim no caso cidades urbanas. Quando fala a palavra cidade você já relaciona ao urbano. Agora, no momento, como eu estou morando na Barra do Jucu que é um lugar muito tranquilo, quando eu penso em cidade penso em Vitória e Centro de Vila Velha, né? Então, esse espaço urbano, a cidade como espaço urbano. E esse espaço urbano concretado me causa muito calor e cansaço, eu me sinto muito cansada. Eu fico 10 minutos na cidade, nessa cidade urbana, quente, cheia de concreto com muito transito. Então, é uma sensação de estafa, mental, física mesmo, como estar dentro de um turbilhão de informações, né? e ter que processar isso tudo, além de mentalmente também fisicamente. Estar atento todo tempo, ter que estar muito alerta, também (ENTREVISTADO).

Experiência de cidade/temporalidade tão distante da ex-moradora paulista. Vitória, cidade-concreto, que coloca este habitante, que se vê fora dessa urbanidade, em alerta, levando o corpo a um cansaço.

Vitória assume várias facetas na organização da vida das pessoas que por ela circula. Desde a cidade casa, a cidade trabalho, a cidade estudo, a cidade lazer, uma infinidade de cidades que compõe uma só e mesma cidade. Tem a cidade do rico, do pobre, do endividado, do que não tem casa e do que mora em uma cobertura, do que vive na Ilha do Boi, em casas que valem mais de 1 milhão e do que tem que lutar para pagar seu aluguel nos bairros "mais baratos". 
Diversas realidades que coexistem e coabitam Vitória. E como elas se esbarram? Como se encontram? Onde se tensionam? Guberman (2009) afirma: as cidades não constituem, somente, fenômeno físico, mas um modo de ocupar e de promover fenômenos expressivos, bem como engendrar tensões na vida social.

Por outro lado também ela [a cidade] causa muita indignação, né? Porque a gente vê outras pessoas que não têm a chance de viver essa cidade desse jeito, que estão no submundo dessa cidade, que estão afastadas dos lugares bonitos e são responsáveis por criar uma outra cidade, inventar uma outra cidade, que não é só essa de beleza, mas que é exploratória e explorada, também. Pessoas que vivem nos escombros dessa cidade, que vegetam nessa cidade, que criam nessa cidade, que procriam nessa cidade. Eu que trabalho com população de rua, vejo que existem, pelo menos, duas cidades dentro de Vitória. Não é que a cidade da população de rua seja feia e a outra bonita, mas se trata de uma outra cidade. A cidade de quem está em situação de vulnerabilidade é uma outra cidade que está dentro dessa cidade. Não quer dizer que ela se torna menos bonita em função disso, mas é um outro olhar que se tem que ter, que não é só do brilho, mas é um outro tipo de beleza. Também sem querer romantizar aqui essa cidade mais vulnerável, ou mais pobre que explora, que violenta, que é algumas vezes justa, algumas vezes injusta. Mas eu, que de alguma forma consegui me inserir nessa outra cidade, quando eu entro dentro dela, eu me sinto igual a ela, eu sinto que eu faço parte dela. E, às vezes, algumas pessoas precisam me lembrar que eu não componho essa cidade, que eu estou na outra cidade. Que às vezes eu esqueço disso. Muitas vezes eu percebo que eu componho essa outra cidade. Na verdade que foi essa convivência tanto tempo com essa outra cidade, com essas outras pessoas que compõem essa cidade, com esse outro modo de viver que me fez sentir também não é pertencente, mas não uma estranha dentro dela. Não me senti um estrangeiro dentro dela. Torná-la visível, eu acho que é isso, pra mim ela ficou visível (ENTREVISTADO).

As falas insistem em compor uma cidade bruta, do combate, do embate. E é isto que fica marcado nessas falas, o embate de forças que se sustentam em meio à cidade. Expressões que exprimem, em um primeiro olhar, sensações. Sensações moventes de uma cidade, que como esta, estão sempre a se redesenhar.

Tem sinais de vários tempos na cidade de hoje, não tem um determinismo, depende da gente, também. Tudo é relativo, nunca

URBANA, V.5, n6, mar.2013 - Dossiê: Urbanistas e Urbanismo- CIEC/UNICAMP 
é fechado no agora e pronto, vamos caminhar, sempre - quer dizer, até nossa morte, e uma vida é muita coisa, tem muita coisa na vida. Então é um fato de perspectiva, isso que é interessante. No tempo, em tudo (ENTREVISTADO).

Acompanhando o pensamento perspectivista do entrevistado acima, somos convidados a lançar um olhar outro, uma atenção outra acerca do tempo na cidade, talvez, afirmar este encontro como um importante expoente para a percepção da subjetividade contemporânea, para o delineamento dos contornos que estão se fabricando nesta cidade - uma cidade singular, embora siga vários padrões globais.

Estar consoante à invenção, à inventividade de outros tempos citadinos, logo, de outras formas de vida e até de outras relações com o lugar, com essa cidade que não é uma sentença, mas uma abertura para variadas experimentações; um desafio que nos perpassa. De acordo com Peixoto (2004), a cidade contemporânea é o cruzamento entre diferentes tempos e entre diversos suportes e tipos de imagens.

Perspectivar, ativar um modo de destoar:

Ali na frente do Palácio Anchieta tem uma estátua de Dona Domingas, que é o nome de uma mulher que morava em Santo Antônio e rodava pelo Centro com um saco de papelão contando história, conversando com o pessoal e todo mundo respeitava ela, sabe? No Brasil, se eu não me engano, é a única estátua de um mendigo. Acho que essas coisa vão contando uma certa história sobre a cidade, sobre o tempo. É porque as pessoas não param para ver aquela estátua, né? Elas não têm tempo pra ver a estátua, para saber da história da cidade (ENTREVISTADO).

Parar para olhar, deixa-se ver por uma estátua de uma mendiga edificada à posteridade. Algo de grandioso vindo do que se considera menor, marginal. Onde fica essa estátua? Será que o corpo desacostumou-se de olhar? Ou, estamos sempre tão distraídos, que não nos apercebemos dos detalhes que irrompem?

Agora, quando é a sua cidade você precisa exercitar uma certa capacidade de voo livre, já que está meio acostumado com tudo... a gente perde um pouco, por exemplo, estando em Vitoria, Vila Velha, tenho muita dificuldade de fazer isso, de andar por andar, 
de explorar, como é bacana fazer quando você está nesses espaços. Mas precisamos tentar, é nosso olhar que tem que se reeducar; rever, para ver (ENTREVISTADO).

Rever para ver, de fato. Reeducar o olhar. Questão de pensar/sentir a cidade por uma outra ótica, com outros olhos ou com alguns óculos. Seria mesmo preciso sair da cidade para potencializar seu tempo?

João do Rio falava que a rua não se modifica. Mentira. João do Rio tava muito doido quando ele disse isso, duvido se ele tivesse vivendo hoje ele falaria isso. Claro que estava falando de um Rio do começo do século passado e tal, muito mais lento, tinha uma dinâmica que era mais lenta, agora não sei, eu acho que eu já vi Vitórias tão diferentes, sabe? A Vitória da minha infância, a Vitória cheia de paralelepípedo, de correr atrás do fumacê, de ir pra escolinha com 40 mil amiguinhos e todo mundo zoando e aquela coisa dos perigos, inclusive, você ia pra escola a tinha que ficar atento aso pivetes, tinha aquela coisa do pivete que era o garoto da outra cidade fora da cidade, né? que viria e ele era malvado e não sei o que... aquelas coisas estúpidas... depois a cidade do adolescente, que você começa a fugir das amarras dos pais e conhecer a cidade noturna, você começa a descobrir a rua e também ser marcado, você começa a descobrir aquela cidade e se marcar nela. E a cidade vai mudando com o tempo. A cidade, por exemplo, eu comecei a viajar muito na época que eu entrei na faculdade e aí Vitória começou a ser uma cidade em comparação com outras, porque aí eu ia pra Taubaté, eu ia para SP, ia pra Salvador, ia pra Curitiba, ia pra não sei aonde e toda vez que eu voltava para Vitória tinha essa coisa, Vitória já se tornava outra. Eu no curso de arquitetura, Vitória se tornava mais outra ainda, né? (ENTREVISTADO).

\section{Temos todo tempo do mundo}

Esse desenho de experimentações diferenciadas de tempos na cidade encorpados pelos entrevistados instigou-nos ir ao encontro de modos de levar a vida que são marcados por uma certa ruptura com um modo contemporâneo de existir. Como metodologia de pesquisa, nos dispusemos a ouvir vozes destoantes. E são essas vozes destoantes que apresentaremos a seguir. Com elas, um traçado de modos outros de existir. Algumas trabalham com arte, outras fazem de sua vida uma arte.

URBANA, V.5, n6, mar.2013 - Dossiê: Urbanistas e Urbanismo- CIEC/UNICAMP 
O modo como entendemos arte e estes fazeres com a arte, é corroborado por Levy (2011, p.100): "Fazer do pensamento e da arte uma experiência do fora pressupõe o contato com uma violência que nos tira do campo da recognição e nos lança diante do acaso, onde nada é previsível, onde nossas relações com o senso comum são rompidas, abalando certezas e verdades".

Nessas conversas, interessávamo-nos as micropolíticas resistentes fabricadas no dia a dia, numa luta constante; um enfrentamento incansável consigo mesmo, em primeiro lugar, e, que nos remetem a re-existir, a pensar outra vez nosso modo de existir, nos esquivando continuamente de toda e qualquer identidade: "Toda identidade é sempre precária e provisória [...] a identidade e o mesmo são apenas disfarces de um ser que é múltiplo e díspar" (SCHÖPKE, 2005, p. 218).

$\mathrm{Na}$ esquiva destes disfarces, que muitas vezes insistimos em vestir, falamos de arte e também de vida. Em outras palavras, de práticas de vida e de respeito à temporalidade imanente: não uma temporalidade individualizada, nem de uma individualização da vida, mas das temporalidades singulares que, assim como a subjetividade, mudam constantemente seus contornos e que se constroem no encontro, no embate de forças e de tempos e se fabricam de modo singelo em cada um, compondo em cada vida seu tempo único, fruto dessa mistura insensata, que se dá no viver e no tempo em que estamos incrustados.

Estamos afirmando outros modos de existir, uma vida afirmativa, por isso, não optamos por enclausurar as pessoas que se dispuseram a participar da pesquisa em uma única definição, que poderia ser tomada, inclusive, como uma noção-identidade; já que cada pessoa compõe um bloco de coisas, sensações e devires que Ihes perpassam.

Criamos, com isso, uma verdade que faz mal as formas bem assentadas em conformidades e em lugares de segurança. Entretanto, até onde a fabulação da nossa verdade, ainda que bem intencionada, esteja criando personagens e não dialogando com as pessoas que marcaram nosso trabalho? Ou ainda: até onde conseguimos dar visibilidade ao para além e 
para aquém do que criamos? Como dar visibilidade ao devir das conversas?

Estamos conversando com estes sujeitos que têm nome, mas, ao longo da conversa, percebemos como eles assumem outros rostos, como outros nomes, não se fechando ao tempo, à subjetividade. Essas pessoas não estão confinadas em um eu-nome, estão abertas e isso é o que mais lhes marca e a este texto. Entendemos que essa abertura compõe um caminhar torto, manco, menor, e nos aponta constituições de outros modos de vida e de fazer, de vontade de potência, de coragem com a verdade, com isso, concorrem para a feitura de outras temporalidades..

A verdadeira vida não é mais representada como essa existência consumada, que levaria à perfeição qualidades ou virtudes que os destinos ordinários só ressaltam com fraco brilho. Ela se torna, com os cínicos, uma vida escandalosa, inquietante, uma vida 'outra', imediatamente rejeitada, marginalizada. [...] essa vida outra constitui ao mesmo tempo a crítica do mundo existente e sustenta o chamado a um 'outro mundo'. A verdadeira vida se manifesta, assim, como uma vida outra que faz irromper a exigência de um mundo diferente (FOUCAULT, 2011, p. 313-314).

O modo como fazem, como vivem, foi o que fez brilhar verdadeiramente nossos olhos, brilhar os olhos com esse fogo que veio para o entre nós - por darem às suas vidas a pulsão necessária para que delas não se arrependam pelo que não fizeram; por viverem a verdade consigo, a vontade de potência, a superação do homem - com esse fogo misterioso do olhar, podemos já sentir o calor somente ao nos aproximarmos para uma conversa.

E saímos, em contato com esse fogo, inevitavelmente aquecidos nos tiram do frio em que muitas vezes nos isolamos, do frio ilusivo do eu, pois, "[...] antes do Ser, há a política" (DELEUZE; GUATTARI, 1996, p. 28).

As vidas das quais falamos percorrem as mais variadas linhas, muitas vezes linhas tortuosas, outras, linhas potentes, mas linhas que, de um modo ou de outro, nos levam a caminhos operantes de resistência e nos fazem perceber, através de suas práticas e intensidades, as diferentes temporalidades que as compõem no mundo e com a qual se conectam: 
respeitando, acima de tudo, isso mesmo - essa verdade de si, como uma constituição de si.

Vidas que se movem, mais ainda: vidas que têm como maior característica o como se movem e o que lhes move. Moveres e fluxos diversos, instigantes, potentes. Arte permeando e atravessando as vidas, fazendo com elas singularidades micropolíticas, potências no cotidiano do mundo, fazendo, enfim, delas a maior das artes.

Artistas que utilizam dos mais variados materiais, e em alguns casos, sem o consentimento de um diploma de graduação. Contudo, sua arte é, sobretudo, do cotidiano. Artistas da vida, que em suas vidas e em seu viver, trazem a força micropolítica da arte, a potência da arte como operadora e forjadora de resistências. E para compor com isso, que juntos nos potencializemos em conversas, em encontros, numa micropolítica do cotidiano.

Mas o que é precisamente um encontro com alguém de quem se gosta? É um encontro com alguém, ou com animais que vêm povoar-nos, ou com ideias que nos invadem, como movimentos que nos comovem, sons que nos atravessam? (DELEUZE, 1996, p. 21).

As pessoas em questão foram escolhidas por suas escolhas, por suas práticas de vida, de viver, de trabalho, de relação com o mundo, que muitas vezes nos apontam o mais simples: que nos tornemos um pouco mais sensíveis.

A simplicidade que compõe viver uma vida verdadeira é o limite, o desafio, a mais potente das armas. Vidas que seguem sem emprego formal, que lutam diariamente por se manterem num mundo que opera por modos capitalistas, vidas que se fortalecem com isso, com suas resistências cotidianas, nessa luta irremediável com o que está dado, na tentativa recorrente de atravessar isso já dado e construir uma outra coisa.

Talvez com a arte, talvez nessa confluência ente a arte e a vida e a resistência e a temporalidade: todas em abertura, todas em construção.

Necessitamos das artes para não morrermos. As artes falam conosco, as artes dizem-nos coisas, não se calam, não nos 
deixam no silêncio, não nos deixam naquele silêncio em que se morre de tédio, naquele silêncio das casas, aquele silêncio das casas onde há livros e uma pessoa anda de assoalhada em assoalhada cheia de fome de livros. [...] é sempre duro apercebermo-nos de que estamos mortos (MANTERO apud PELBART, 2007, p. 44).

É na luta cotidiana contra esse morrer que é mais da ordem de um matar-se que se fez esta pesquisa, para que nossa sede de livros não fosse apenas de livros, para que ela desembocasse em algo mais, para que dela pudesse brotar criação e partilha dessa mesma criação. Conclamamos a todos que se aventurarem a ler este artigo a deixarmos os modos titereiros do capitalismo descansarem - o que é um trabalho duríssimo e rigoroso, pois nos coloca em questão com o mundo em que estamos e com o mundo que queremos afirmar. A seguir, pequenos trechos de fragmentos das entrevistas que compuseram esta pesquisa, falas que trazem em algumas palavras um pouco das vidas dessas pessoas.

Esse poder da arte como minha terapia, assim, como minha forma de aterrissar, minha forma de dar forma a angústias, ou coisas que eu acredito, dar forma a muitas vidas, muitos fluxos interiores que a gente tem. Isso começou com uma pesquisa pelo corpo que foi muito importante, ver ele como essa primeira ferramenta artística, e enxergar como: todo mundo pode fazer arte a partir de si. O canto, as pessoas falam: 'ah, não sei cantar, então não canto'. Ou então: 'ah, não sei dançar, então, não danço'. Então essa oportunidade de estar vivo para mim é explorar quantas coisas eu quero, todo mundo pode cantar, todo mundo pode dançar. Não sei me deixar levar por esses medos de cada vez mais ter que se especializar, especializar em alguma coisa [...]. Levar o corpo que você tem, quando joga futebol de manhã - você chega lá no engarrafamento, na cidade e você tenta levar esse corpo, nesse momento, um corpo de cidade, de engarrafamento, de ficar no ônibus parado, a um outro espaço, como a natureza, que seja tranquilo e silencioso. Então, brincar com essa transitoriedade. Porque, para mim é uma busca, tentar pesquisar meu corpo, minha realidade, que não é somente esta que habita a natureza e sim uma grande cidade, como foi em Bogotá e São Paulo, cidades em que morei. Tinha que trabalhar meu corpo para não me encher de tudo de ruim que pode haver na cidade, nós não podemos estar tão abertos nela, tem que ter uma pele que 
camufle e que filtre, também, as coisas. Tanto Bogotá como São Paulo, ao mesmo tempo em que elas oferecem esse pequeno inferno, elas oferecem meio que um paraíso também de você encontrar todo tipo de possibilidades para se conectar com seu corpo, dentro de cidades. Práticas de resistência (ARTISTA PLÁSTICA).

Eu procuro ficar bem com o mundo, não no sentido de salvador dele, mas um bem que me faz bem, também. Como usar a bicicleta... que não é uma questão de preocupação com o mundo, de diminuir a poluição do mundo. É porque eu gosto de bicicleta, de pedalar, então, na verdade acho que caminha junto, se a gente for ver um sentimento, parece que o que faz bem pro mundo, faz bem pra a gente, também. Eu gosto de estar bem pra ficar em paz, tranquilo, mesmo nesse tempo caótico. Só de deslocamento pro trabalho levava 1 hora ou mais, dependendo do lugar, só para chegar lá. Por causa disso que eu decidi parar de vez de andar de ônibus [...].Tô amando ficar à toa. E agora meu objetivo, além de trabalhar com o que gosto, é trabalhar pra mim mesmo, eu faço meu horário, porque antes eu trabalhava com o que gosto, mas muito tempo, agora eu quero trabalhar na minha área, mas eu construindo o meu ritmo. Eu faço o meu tempo, mais independente do que eu já era. Parece que quando a gente entra no ritmo fica difícil enxergar, tem até umas chargezinhas naquele livro 'o apocalipse motorizado', aí tem o cara falando: ah, não aguento tanto trabalho, mas eu tenho que pagar as contas do meu carro, eu não aguento esse carro, mas eu tenho que ir pro meu trabalho rápido [...]. Tipo assim, você cai nesse modelão, você precisa de dinheiro, porque você tá gerando mais conta pra você pagar e você precisa de mais, então você não pode parar de trabalhar. Aí fica nessa espiral maluca, a gente pode parar de consumir um pouco pra não gerar tanta conta, pra parar com essa demanda de ter que trabalhar tanto, produzir tanto. E esse tipo de vida é viciante mesmo. Quando eu rompi, fiquei até com um frio na barriga, tipo: e agora? (CICLISTA/ARTISTA VISUAL).

Nunca tive patrão, assim que não sei na pele como seria ser comandada, mas, não tenho curiosidade. Gosto da liberdade conferida desde os projetos criados por gente mesmo, da adrenalina, da cabeça girando com tantas ideias antes de dormir, de ter que levantar e escrever um pouco pra descarregar... sinto que não poderia viver sem projetar, sem criar e colocar em prática estas ideias e gosto de saber que algumas coisas plasmadas em muito tempo seguem se desenvolvendo e se construindo, assim como um caminho, onde cada pedra e planta vão encontrando lugar, deixando o espaço pra passar tranquilo, com clareza [...].Pensei, também, 
a respeito da especialização e descobri que de verdade eu não gosto dela, não quero ter um movimento perfeito, mas sim muitos movimentos que têm como beleza sua própria imperfeição, sua maneira tosca de ser [...].Desde algum tempo, a necessidade da transitoriedade me faz ter vontade de migrar, migrar, viajar, olhar, ver coisas novas e sentir outros mundos me invadindo e ser parte disso e deixar algo; sempre pra poder voltar. Comecei minha viagem há um ano e meio e sei que ela apenas começou, conheci outros lugares e outra gente e a vontade de seguir só cresceu. Desde aí minhas ideias sempre vão no sentido da mobilidade e venho pensando em maneiras urgentes e desesperadas de seguir viajando, e seguir criando e seguir aprendendo. No ano passado a ideia de um espaço móbile de cultura audiovisual me perseguiu por onde andei, desde quando pisei na Colômbia as ideias me fluem neste sentido, primeiro pensei que poderia ser uma mostra de vídeo, mas vi que não, pensei que poderia ser uma performance com a virtualidade projetada e vi que por aí sim, pensei que o corpo tem que estar presente na ação e fui pensar porque queria esse corpo presente. Assim, vi que esse é o diálogo entre o primitivo, tosco, artesanal com o virtual, binário, exato e quadrado da virtualidade, inegáveis riquezas cada um desses universos que estão presentes na latinoamérica, cidades sem luz elétrica, sem conexão com internet, sem digitalização de arquivos, gente que está ainda vivendo na natureza mais exuberante, e gente que está vivendo o momento do descobrimento da roda, nas suas roças, com seus moinhos de vento, e cidades urbanizadas, conectadas, com wifi e metrô [...] (VIDEOMAKER/EDITORA/PRODUTORA).

Rio, mar, água... Desejo de aguar. Vontade que percorre um corpo e uma vida. Movimento que nos leva noutras direções, trilhas, pessoas, lugares, sentimentos, coisas, troços, encantos tantos. Há todo um caminho que a água percorre. Gelo, vapor, suor, urina... Intercambiar para mim se parece com este estado de ser líquido, transbordante, fluido, nômade. Ir ao encontro aquilo que pouco se sabe, ou mesmo daquilo onde nada é sabido. Aventura, deslocamento, deságue. Intercambiar é desarranjar um pouco a ordem das coisas e da vida. É claro que isso é coisa de quem ama 'artistagem', malandragem e que tenta gingar uma certa malemolência no corpo. Desfaz corpo e cabeça dura pra construir corpo mole, que degela; molham os outros com seus respingos e sacolejos fortuitos. [...] Cheia de empolgação e emoção, a gente segue os primeiros passos, molha o papel com as primeiras palavras. Coisa de gente que se atrapalha pelos excessos, mas que ainda não aprendeu outra 
maneira de começar que não seja pelo SIM (ARTISTA VISUAL/PROFESSORA/PERFORMER).

Eu tenho sempre uma relação com o caminho, por andar de bicicleta, andar a pé, então a gente vai notando a cidade de uma outra maneira, vai notando tudo. E tem uma outra coisa que desperta, um tipo de agonia, de insatisfação e isso vem muito da publicidade. O lance dos outdoors, passar e ver tanta publicidade, aí dá vontade de brincar com isso, de dizer: 'ô, se liga, não é por aí, né?'. E tem a ver com a bicicleta, essas percepções e brincadeiras, andar sempre de bicicleta e perceber uma cidade e se sentir cidade, autorizado pra intervir nessa cidade. Tem gente que vai achar agressivo intervir em outdoor, mas pra mim o agressivo já é a existência do próprio outdoor. Então, não estou sendo agressivo, eu estou tentando fazer um pouco de poesia no meio da publicidade e dar visibilidade para certas coisas, como, por exemplo, a poluição ferrada que a Vale faz na cidade, esse transtorno que deixa muita gente com alergia e outras coisas pulmonares ainda piores (CICLISTA/ARTISTA VISUAL).

Esse trabalho coletivo me forma enquanto pessoa, e, também, faz eu me perder um pouco de mim... um bem que é maior que o EU, né? É essa a resistência que nasce desse coletivo, que me chama. Talvez, isso fique mais forte nos tempos que a gente vive hoje, em que o isolamento é muito intenso, que a questão do individualismo é muito forte, por isso a importância fundamental dos grupos (ARTISTA CÊNICA).

O que a gente tenta é conseguir andar sem ser manipulado, fazer seu próprio ritmo. Isso é uma coisa que eu sinto e penso sobre tudo, como você usufruir de algo sem ser dominado por aquilo, não só no campo social, não só em relação ao dinheiro... Não ser dominado, mas estar dentro, não estar fora. Em 2006, começamos essa jornada de mudança. Nós já vivíamos de uma forma alternativa, mas um pouquinho alternativa, porque ainda tínhamos emprego formal e 'perdíamos' boa parte do nosso dia, nele. E para mudar na marra, aconteceu uma fatalidade... A gente sofreu um acidente bem grave de moto... E eu tenho um filho especial, ele é autista, tem 12 anos hoje, mas na época ele tinha 5. E com esse acidente ele teve que ir pro Rio de Janeiro, ficar com o pai biológico, para que me recuperasse. Eu fui no fundo do poço, fiquei muito mal naquela época... deprimida... mas quando se sai do fundo do poço, sempre se traz uma oportunidade de fazer de outro jeito, de viver de outro jeito. A partir daí, ao nos permitimos viver outras coisas, buscá-las, tivemos bons encontros no caminho, aprendemos as habilidades das quais a gente tira nossa fonte de renda hoje, que são o tambor e a 
tecelagem (TECELÕES/FEITORES DE TAMBOR).

Com essa conjunção de falas que unidas ao acaso constroem uma outra coisa, um outro discurso, afirmamos que existem modos de viver diferenciados que se colocam como operadores de resistência, forjadores de uma micropolítica do cotidiano. Com isso, não estamos afirmando que apenas as pessoas que não têm emprego formal ou que se enveredam por uma vida alternativa/artística conseguem ou podem viver uma temporalidade outra na cidade, afirmamos que é necessário um caminhar ético-estético e político para fazer da vida o que se quer, com autonomia. Em outras palavras, é necessário que possa se viver inventivamente, com coragem e labor de si.

\section{Referências}

AUGÉ, M. (2010). Por uma antropologia da mobilidade. Tradução de Bruno Cesar Cavalcanti e Rachel Rocha de Almeida Barros. Maceió: EDUFAL/UNESP.

CALVINO, Í (2008). As cidades invisíveis. Tradução de Diogo Mainardi. São Paulo: Companhia das Letras.

DELEUZE, G.; GUATTARI, F. (1996). Mil platôs: capitalismo e esquizofrenia. Rio de Janeiro: Ed.34.v. 3.

FOUCAULT, M. (2011). A coragem da verdade. São Paulo: Martins Fontes.

GUBERMAN, M. (2009).Provocações da cidade. Rio de Janeiro: UFRJ.

LEVY, T. S. (2011).A experiência do fora Blanchot, Foucault e Deleuze. Rio de Janeiro: Civilização Brasileira.

MANSO, C. C. (2010). Narrativas do cegar: (re)criações de um corpo. 122 f. Dissertação (Mestrado em Psicologia) - Instituto de Ciências Humanas e Filosofia, Universidade Federal Fluminense, Niterói.

PEIXOTO, N. B. (2004).Paisagens urbanas. São Paulo: SENAC, 2004.

PELBART, P. P. (1993). A nau do tempo rei: sete ensaios sobre o tempo da loucura. Rio de Janeiro: Imago.

PELBART, P.P. (2007). O tempo não-reconciliado. São Paulo: Perspectiva. 
SANTOS, J. J. G.; LOPES, K. J. M.; PROTÁZIO, M. M. (2010). Modos de dizer e a vida se fazendo numa feira livre em Aracaju. In: SEMANA DE CIÊNCIAS SOCIAIS, VIII, 2010, São Cristóvão, SE. Anais... Sergipe: UFS.

SCHÖPKE, R (2005). O eterno etorno de Nietzsche: seleção ou repetição? ORLANDI, Luis B. L.; (Org.). A diferença. Campinas: Editora Unicamp.

SERRES, M. (1993). Filosofia mestiça: o terceiro instruído. Lisboa: Instituto Piaget. 